\title{
EFFECT OF INCLUSIONS ON FATIGUE STRENGTH OF HEAT TREATED COMPONENTS
}

Inclusions significantly affect fatigue properties of quenched and tempered parts. Data about inclusions importance in fatigue crack initiation process were acquired within the framework of a systematical fatigue test programme carried out to verify fatigue properties of $\mathrm{CrNiMo(V)}$ steels quenched and tempered to $800 \div 1000 \mathrm{MPa}$ strength. A valuable set of fatigue failures from the high lifetime area was acquired.

Microfractographical analysis of these failures enabled to evaluate critically the influence of inclusions, their dimensions, character and morphology on the initiation and propagation of the fatigue cracks in the area of fatigue strength. Comparison of inclusions size "a" according to Murakami with size determined experimentally was made. Limiting influence of small single inclusions in the structure was shown. Initiation of secondary fatigue cracks on inclusions outside of the fracture initiation area was observed. Danger of the fracture initiation after very high lifetime was confirmed.

\section{Introduction}

Contemporary demands for efficiency and lifetime of plants lead to an increasing amount of heat-treated parts, the strength of which is $800-1000 \mathrm{MPa}$ even in the case of large bulky components. The load-carrying capacity as well as the lifetime of fatigue loaded parts result not only from strength properties, but also from the steel purity and inclusion contents. Modern metallurgical processes of steel production afford new possibilities in this field $[1,2]$.

The present work follows of our previous experiments [3] and deals with the effect of inclusions on fatigue strength. A sufficiently long lifetime is generally required and thus the data on long-term fatigue properties, characterized by fatigue limit above all, are quite indispensable for the construction of plants.

The basis for assessment of the inclusion effect was obtained during the fatigue tests performed on rods of $\mathrm{CrNiMoV}$ and $\mathrm{CrMo}$ steels that were cut from large forgings of ship crankshafts and hydraulic cylinders. The tests were of "stair case" type and were aimed at obtaining statistically supported values of the fatigue limit. To evaluate the effect of inclusions, an extensive set of fatigue failures occurring in the specimens having long lifetimes close to the fatigue limit was investigated.

Previous works [4-6] carried out on heat treated steels showed an unfavourable influence of inclusions (e.g. silicates, aluminates) even at their size of $10 \mu \mathrm{m}$ and this effect became more pronounced with the increasing size of inclusions.

Recent development in fracture mechanics has been connected with some works dealing with the possibilities of a more general evaluation of small inhomogeneities, short cracks, on the fatigue strength. However, the application of fracture mechanics quantities, particularly that of $K$ and $\Delta K$ factors to those small areas seems to be rather problematic [7]. To solve this problem, various engineering modifications have been proposed. The modification of El Haddad et al. [8] is well known and describes the dependence of fatigue properties and that of fatigue limit on inhomogeneity size $\ell$ and on the threshold value of $\Delta K_{\text {th }}$

$$
\Delta \sigma_{t h}=\Delta K_{t h} / \sqrt{\left(\pi\left(\ell_{0}+\ell\right)\right)}
$$

Taking fatigue limit $\Delta \sigma_{t h}=2 \sigma_{C}$ and $\ell=0$, we obtain

$$
\ell_{0}=(1 / \pi)\left(\Delta K_{t h} / 2 \sigma_{C}\right)^{2}
$$

Another modification of relation (1) was made by Lukas and Kunz [9].

Murakami, Endo et al. [10,11] and other authors describe the dependence of fatigue limit $\sigma c[\mathrm{MPa}]$ on strength properties of the base material $[\mathrm{HV}]$ and on the inclusion area $\underline{a}$ as

$$
\sigma_{C}=\Lambda(H V+120) /(\sqrt{a})^{1 / 6}
$$

\footnotetext{
* Vaclav Linhart, Dagmar Mikulova, Ivo Cerny

SVUM a.s., Praha Czech Republic, E-mail: linhart@svum.cz
} 
Thus, the critical size of inclusion on fatigue limit is

$$
a=\left[\Lambda(H V+120) / \sigma_{C}\right]^{12}
$$

where $\underline{a}$ is projected area of the inclusion in the plane perpendicular to the plane of maximum normal stresses. The values of constant $\Lambda$ are 1.43 for the inclusions situated at the surface and 1.56 in the case of inclusions occurring under the surface.

The assessment of the inclusion effect on fatigue properties by means of $\sqrt{a}$ was accepted also by Bomas et al. [12] and Kunz and Lukas [13].

\section{Effect of inclusions on specimens obtained from the hydraulic cylinder}

Forgings of the high capacity press hydraulic cylinders diameter $1580 / 1060 \mathrm{~mm}$ were made of $20 \mathrm{NiCrMoV} 14-6$ steel, the chemical composition of which is as follows (weight \%): $0.19 \mathrm{C} ; 0.36 \mathrm{Mn}$; 1.6 Cr; 3.1 Ni; 0.4 Mo; 0.03 V; 0.016 Al; 0.0059 P; 0.004 S. Statistically processed results of staircase fatigue tension - compression tests $(R=-1)$ carried out on specimens of diameter $8.6 \mathrm{~mm}$ are given in Table 1. The forgings of the second group (No. 5708, 5709 ) were substantially heavier than those of the first one (No. $4758,4759)$

Table 1

\begin{tabular}{|c|c|c|c|c|}
\hline \multirow{2}{*}{$\begin{array}{c}\text { Forging } \\
\text { No. }\end{array}$} & \multirow{2}{*}{$\begin{array}{c}\text { Strength } \\
{[\mathrm{MPa}]}\end{array}$} & \multicolumn{2}{|c|}{ Fatigue limit $\sigma_{C}[\mathrm{MPa}]$} & $\begin{array}{c}\text { Standard deviation } \\
\text { of fatigue limit } \\
{[\mathrm{MPa}]}\end{array}$ \\
\hline 4758 & 801.5 & 417 & 386 & 9.06 \\
\hline 4759 & 789.9 & 406 & 332 & 25.6 \\
\hline 5708 & 874.8 & 387 & 262 & 40.5 \\
\hline 5709 & 859.1 & 387 & 363 & 9.1 \\
\hline
\end{tabular}

It follows from Table 1 that the fatigue limit at the probability level $P=50 \%$ of the forgings with higher strength (Nos. 5708, 5709 ) is surprisingly lower $-c$. by $10 \%$ - than that of the forgings with lower strength (Nos. 4758, 4759).

As expected, the failure occurred in several specimens in the region of high cycle loading close to the fatigue limit. These specimens were examined by microfractographical microanalysis using JEOL JSM 35 scanning microscope.

In most of cases, the initiation centres of fatigue failure, characteristic by typical rosettes of fine gradual defect growth with radial orientation, were found under the fracture surface even at low magnifications (Fig. 1). The second phase of defect growth which led to fatigue failure took place after the spreading out of original rosette up to the rod surface. Microfractographical examination showed that the initiation of fatigue failure occurred at clusters of granular inclusions with an incompact network (Fig. 1). The length of inclusions is $150-300 \mu \mathrm{m}$, the dimension of their characteristic area $a$ is $6000-46000 \mu^{2}$. It follows from the electron microanalysis carried out on CAMEBAX electron microanalyser that the inclusions are complex and contain a high amount of $\mathrm{Al}$,
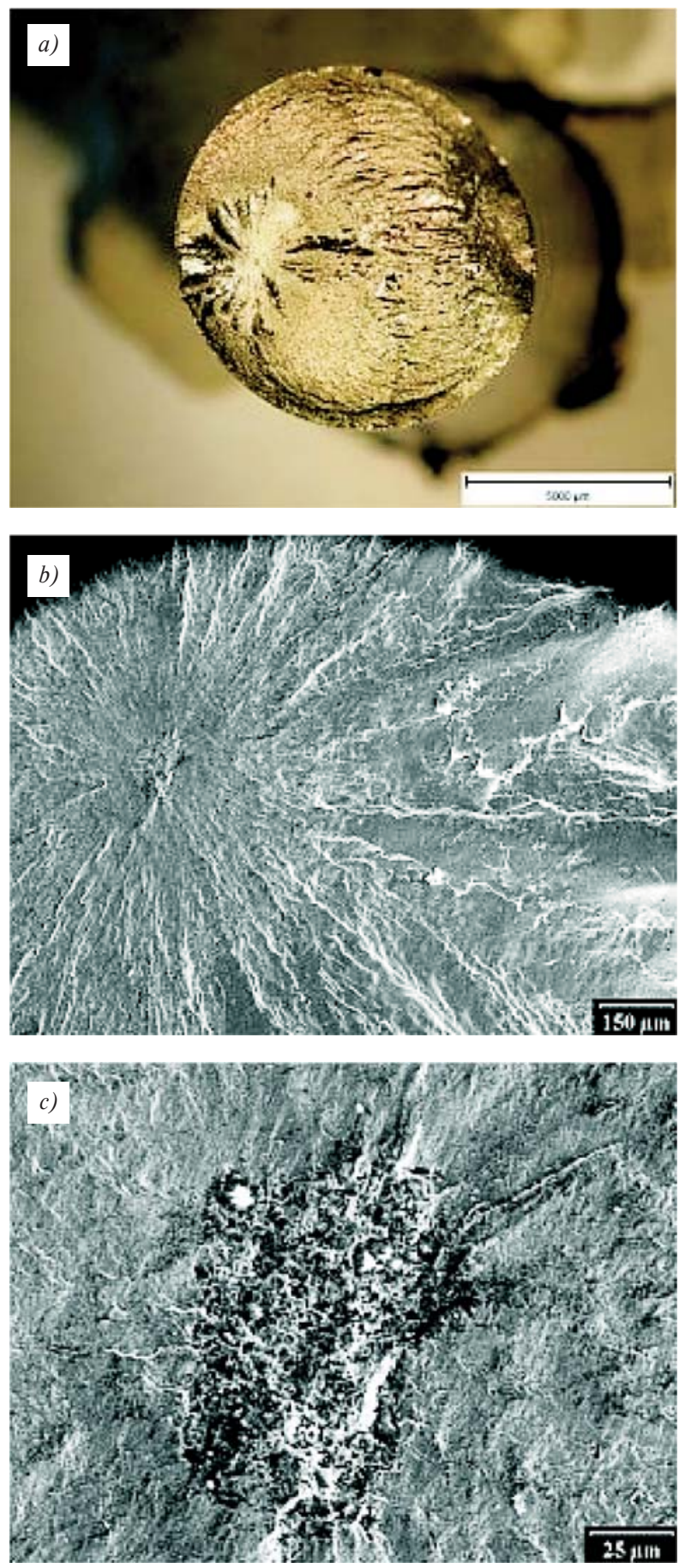

Fig. 1 Initiation fracture rosette under the surface, specimen No. 5708-37 a) macroscopic view, b) microscopic view, c) detail of the cluster 
$\mathrm{Ca}, \mathrm{O}$ and $\mathrm{C}$. They are apparently aluminates $\left(\mathrm{Al}_{2} \mathrm{O}_{3}\right)$ and calcium compounds $\left(\mathrm{CaO}, \mathrm{CaCO}_{3}\right)$.

The occurrence of inclusions lead to a substantial increase in statistical scatter of fatigue limit values in the investigated forgings (Table 1). On the other hand, this result is considerably influenced by a random spacing of clusters and, therefore, it may not be generally valid.

The differences in the spacing of initiation rosette occurring on the fracture surface did not cause, surprisingly, any significant changes of fatigue lifetime.

Surfaces are generally more sensitive to the initiation of fatigue fracture than the regions under the surface. It arises from the greater deformation freedom of surface structural regions. The analysis of fracture relief at the specimen surface under which the initiation rosette occurred showed that the cause of latent tendency of surface layers to the initiation were isolated granular inclusions whose length was rather small, up to some tens of $\mu \mathrm{m}$. It can be expected that in the case of bulky forgings the danger of occurrence of unfavourable inclusion clusters will be quite considerable.

The analysis of the second set of forgings (No.4758, 4759) with higher value of the fatigue limit showed that the fatigue failure initiated, almost without exception, at the specimen surface on groups or smaller clusters of granular inclusions (Figs. 2, 3). These clusters are similar to the larger ones observed in forgings of the first group; their length is $50-150 \mu \mathrm{m}$ and the area reaches the values between 1000 and $13000 \mathrm{um}^{2}$. However, a considerably larger cluster area $\left(50000 \mathrm{um}^{2}\right)$ was also exceptionally observed; in this case, the determined lifetime was very low $\left(3-4.10^{5}\right.$ cycles $)$. The presence of large clusters of inclusions caused in some cases (see Table 1) a greater scatter of fatigue limits whose values were low at the required higher reliability level.

The effect of regions containing sulphide inclusions was found to be quite unimportant in comparison with the influence of gran-

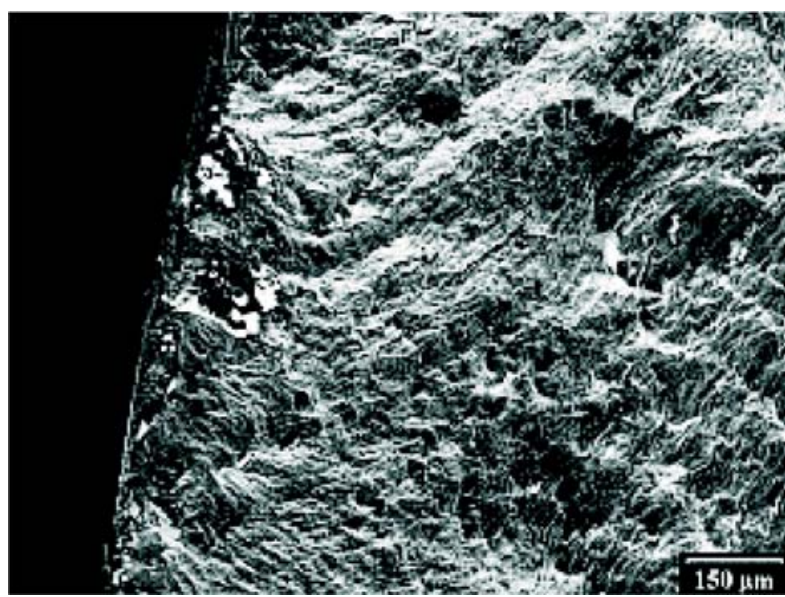

Fig. 2 Group of granular inclusions, specimen No. 759-30

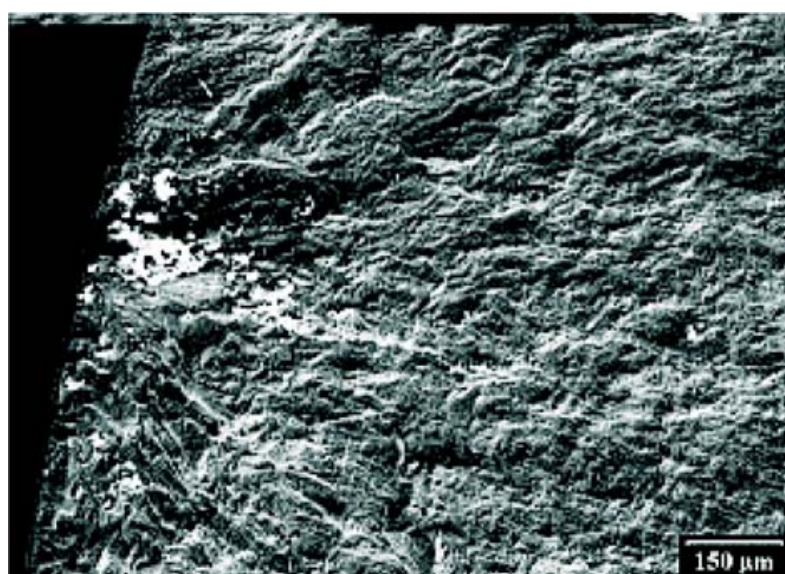

Fig. 3 Cluster of granular inclusions at the initiation area, specimen No. 4759-16

ular complex inclusions. For example, fatigue failure initiated at the surface on the group of granular inclusions with the total area $a=$ $=7400 \mathrm{~mm}^{2}$, but only some weak symptoms of secondary initiation of the fatigue failure were observed at the large sulphide cluster (Fig. 4) with the dimensions $133 \times 200 \mu \mathrm{m}\left(a=20890 \mu \mathrm{m}^{2}\right)$ occurring inside of the same specimen.

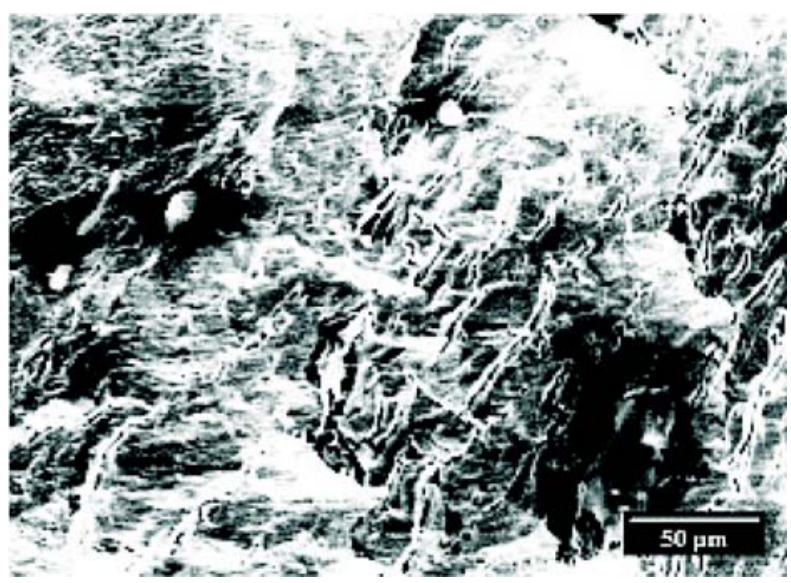

Fig. 4 Cluster of sulphides in fracture surface, specimen No. 4759-16

It was found, similarly to the first group of forgings that the isolated granular inclusions, the size of which was $15-20 \mu \mathrm{m}$ (Fig. 6), occurring in the coarser tempered bainitic structure (Fig. 5) did not lead to initiation of fatigue failure. In this case, the fatigue failure did not initiate on inclusions, but inside the basic quenched structure.

We compared our results with the critical sizes of inclusions determined according to the relations (3) and (4) of Murakami et al. - Tab. 2, for the fatigue limit at the probability levels of 50\% and $95 \%$. The calculated critical values are close - within one order - to those determined metallographically even though the evaluation according to Eqs. (3) and (4) corresponds rather to the con- 


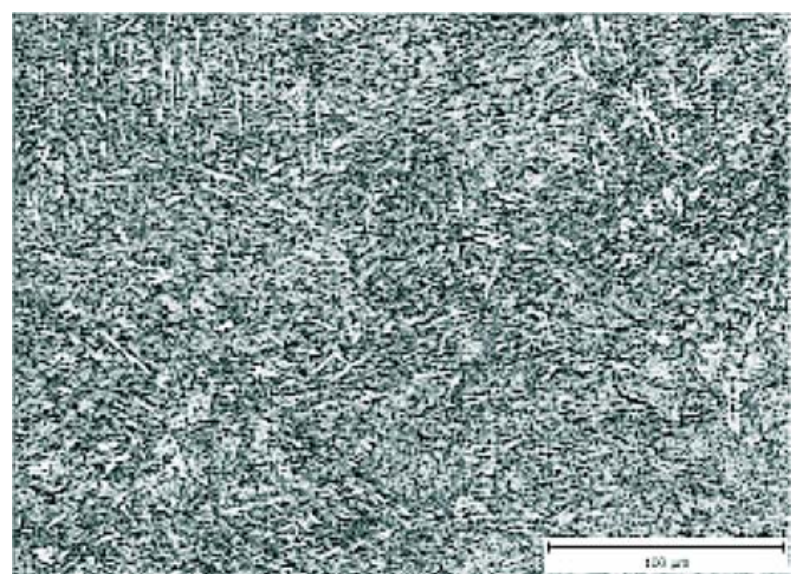

Fig. 5 Fairly coarse tempered bainitic structure

servative approach. This is quite obvious from Fig. 7, where the measured sizes of inclusions at the surface and the calculated values according to relation (4) are given.
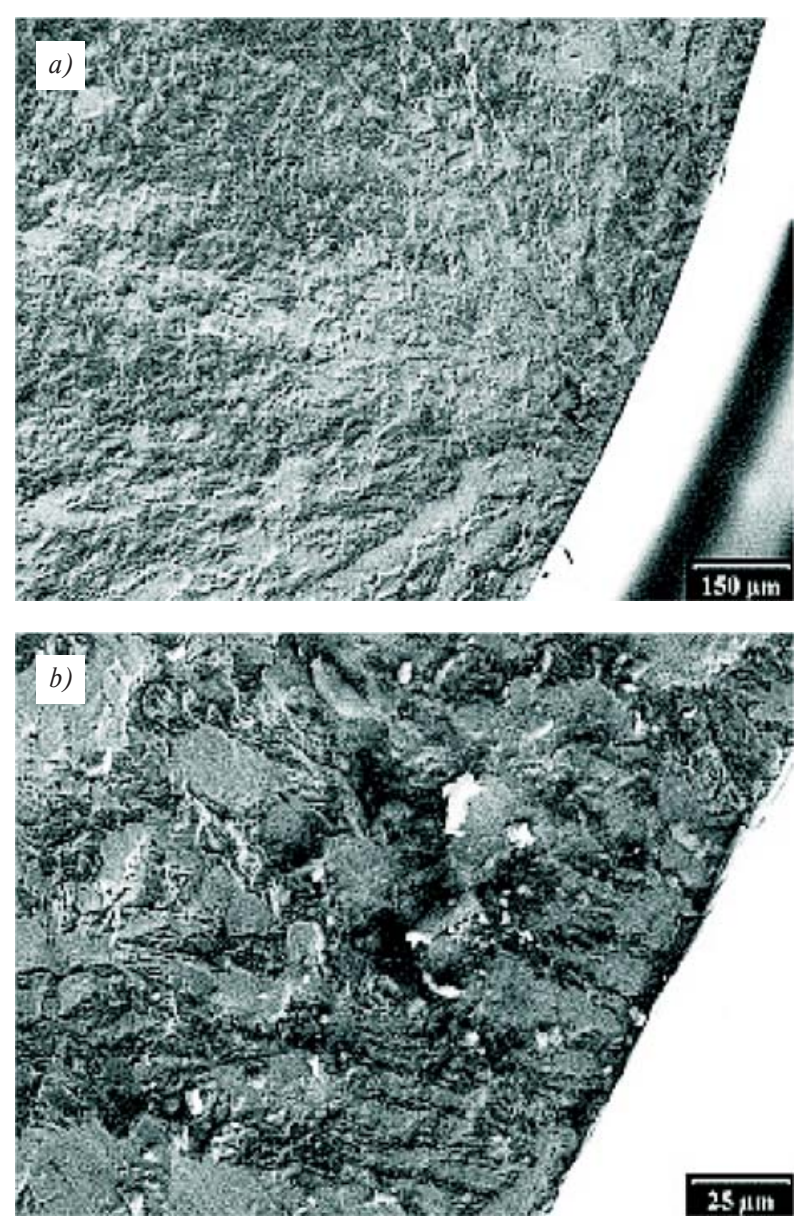

Fig. 6 a), b) Initiation of the fatigue fracture is not practically influenced by isolated granular inclusions, specimen No. 4758-9
Table 2

\begin{tabular}{|c|c|c|c|}
\hline \multirow{2}{*}{$\begin{array}{c}\text { Forging } \\
\text { No. }\end{array}$} & $\begin{array}{c}\text { Surface / } \\
\text { Fracture Area } \\
\text { S / FA }\end{array}$ & \multicolumn{2}{|c|}{ Critical inclusion size "a" $[\mu \mathrm{m}]$} \\
\cline { 3 - 4 } & $\sigma_{C}(\mathrm{P}=50 \%)^{1)}$ & $\sigma_{C}(\mathrm{P}=95 \%)$ \\
\hline \multirow{2}{*}{4758} & $\mathrm{~S}$ & 59 & 102 \\
\cline { 2 - 4 } & $\mathrm{FA}$ & 90.7 & 309 \\
\hline \multirow{2}{*}{4759} & $\mathrm{~S}$ & 45.1 & 504.9 \\
\cline { 2 - 4 } & $\mathrm{FA}$ & 128.1 & 1431.7 \\
\hline \multirow{2}{*}{5708} & $\mathrm{~S}$ & 150.5 & 1623.7 \\
\cline { 2 - 4 } & $\mathrm{FA}$ & 427.6 & 46128.4 \\
\hline \multirow{2}{*}{5709} & $\mathrm{~S}$ & 129.6 & 297 \\
\cline { 2 - 4 } & FA & 368.2 & 843.7 \\
\hline
\end{tabular}

Note 1): Specific concrete $\sigma_{C}$ values - see Table 1

\section{Effect of inclusions in specimens cut from the crankshafts}

The massive crankshaft forgings with the journals of 450 $460 \mathrm{~mm}$ diameter were investigated.

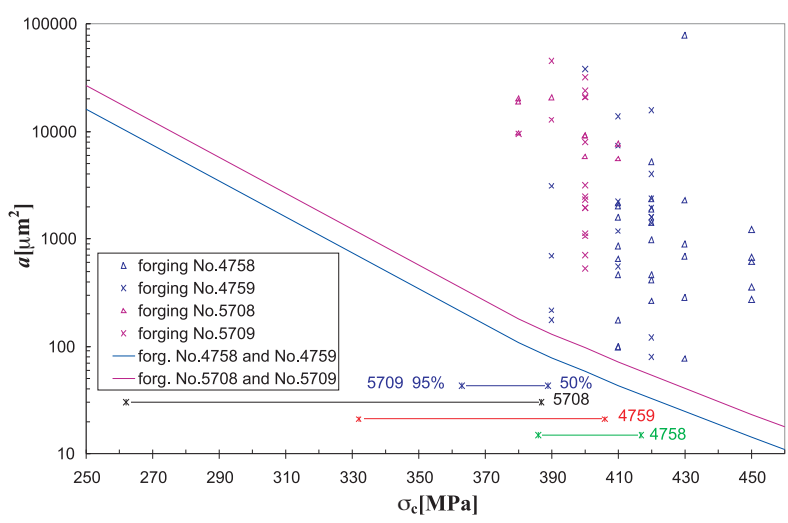

Fig. 7 Comparison of calculated " $a$ " value with the inclusions size determined experimentally

\subsection{CrMo4 steel crankshafts}

The steel of the chemical composition (weight \%) $0.51 \mathrm{C}$; $0.79 \mathrm{Mn} ; 1.18 \mathrm{Cr} ; 0.49 \mathrm{Ni} ; 0.27 \mathrm{Mo} ; 0.1 \mathrm{~V} ; 0.007 \mathrm{P} ; 0.001 \mathrm{~S}$ and with the micropurity according to standards: A $0-0.5$; oxides D 1.5 was heat-treated to the strength $R_{m}=928 \mathrm{MPa}$ and hardness 296 - 320 HV. Resulting tempered structure was characteristic by a needle morphology. Fatigue limit in tension-compression loading $(R=-1)$ was determined with the help of staircase fatigue tests. It reaches the value $\sigma_{C}=441 \mathrm{MPa}$ at the probability level $P=50 \%$ and only $249.5 \mathrm{MPa}$ at the probability level $P=95 \%$.

Macroexamination revealed fatigue failures initiating at the surface in all specimens. Microfractographical investigation showed 

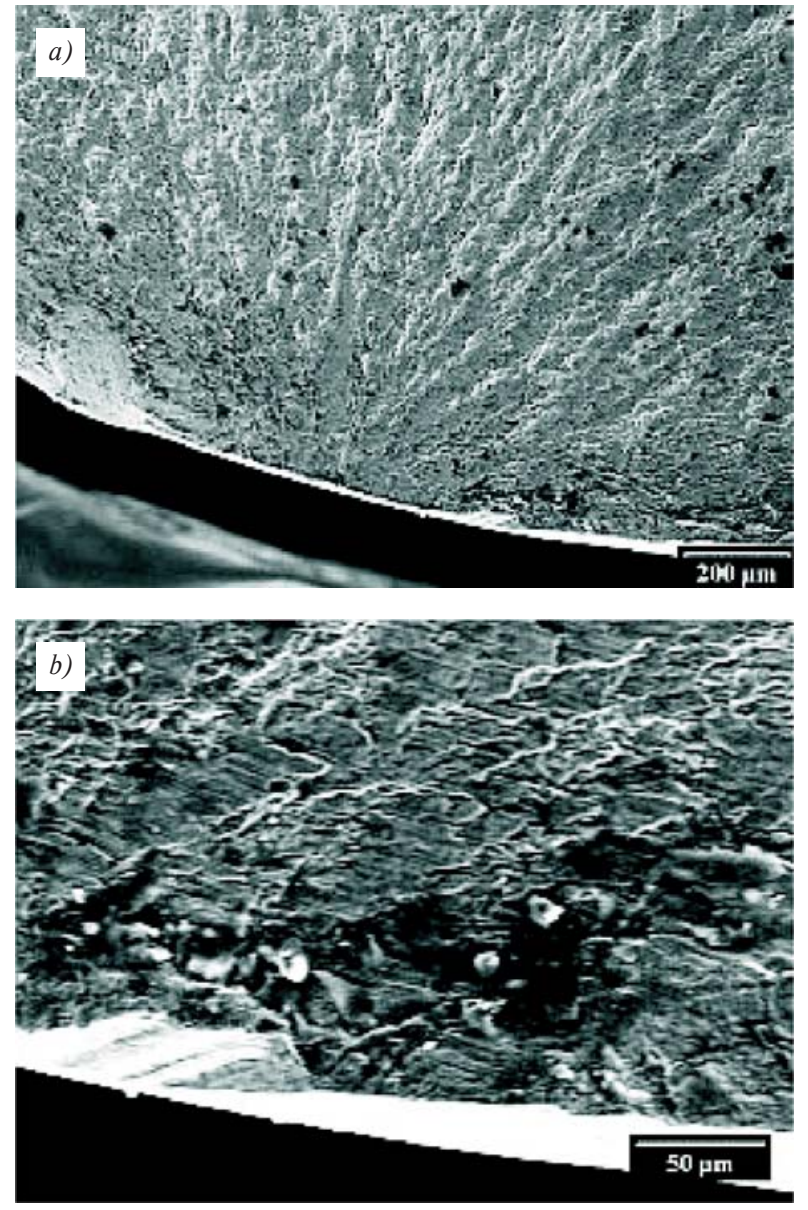

Fig. 8 a), b) Initiation of the fatigue fracture is not influenced by isolated fine granular inclusions, specimen No. P7 cut from the crankshaft

the occurrence of inclusions (apparently the complex inclusions of aluminates and calcium oxides) in the form of isolated granular particles or groups of the particles. Their typical size is several tens of $\mu \mathrm{m}$ (maximum 100-170 $\mu \mathrm{m}$ ) and their area $a$ at the surface reaches several hundreds of $\mu \mathrm{m}\left(\max .3000 \mu \mathrm{m}^{2}\right)-$ see Fig. 8. It is quite apparent even in this case that the initiation centre of fracture lies outside the region of fine particles, it occurs in the structure of the base material. Fatigue relief is not practically influenced by the presence of granular inclusions. This situation was observed in most cases, but, on the other hand, there are also some specimens where the fracture initiated at the group of inclusions (Fig. 9a, b). A considerable scatter of fatigue tests results, particularly of fatigue limit values at the probability level $95 \%$, can be explained in this way.

\section{2. $34 \mathrm{CrNiMo6}$ steel crankshafts}

The steel of the chemical composition (weight \%) $0.36 \mathrm{C}$; 1.5Cr; $1.45 \mathrm{Ni} ; 0.21 \mathrm{Mo} ; 0.0058 \mathrm{Al} ; 0.0028 \mathrm{P} ; 0.0067 \mathrm{~S} ; 0.0019 \mathrm{~N}$ was heat-treated to the strength $\sigma_{c}=961 \mathrm{MPa}$ and hardness 315
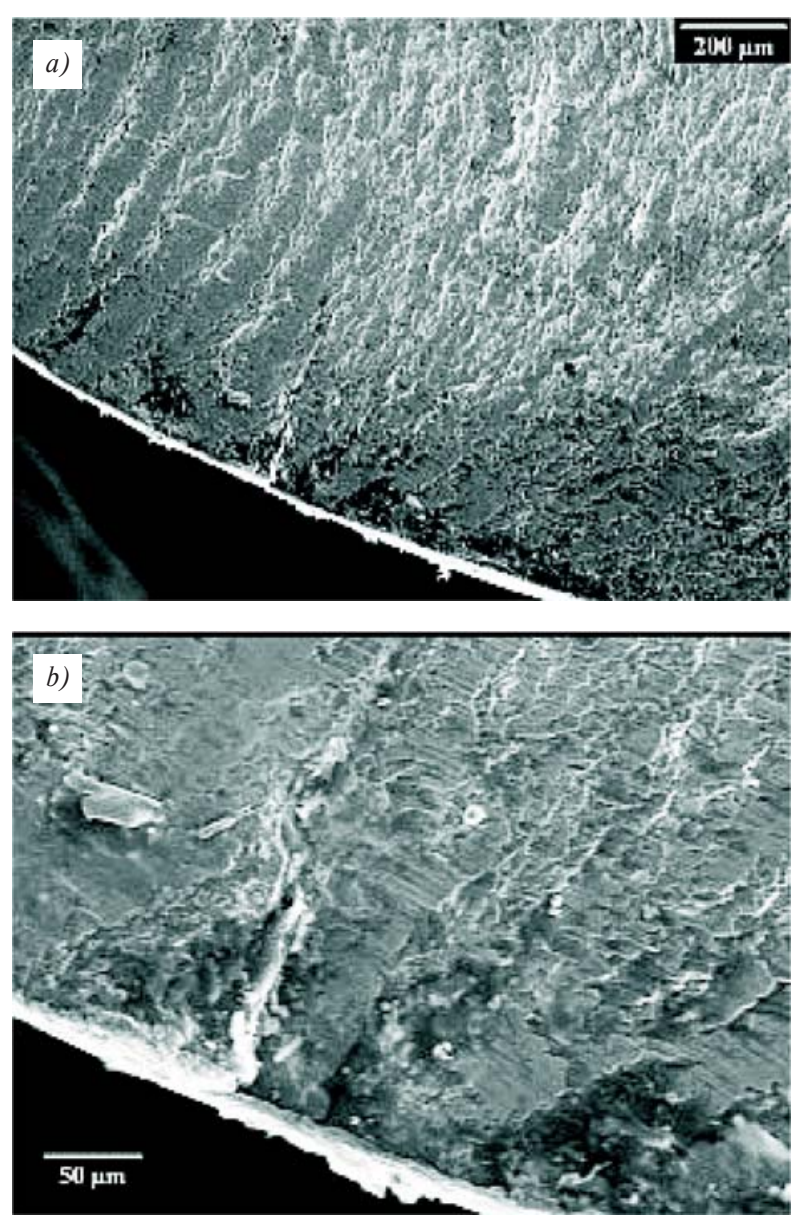

Fig. 9 a), b) Row of fine granular inclusions affected the initiation of fatigue fracture, specimen No. P7 cut from the crankshaft

HV. The fatigue limit in tension-compression loading $(R=-1)$ was determined by staircase fatigue tests again and reached the values $\sigma_{C}=390 \mathrm{MPa}$ at the probability level $P=50 \%$ and $\sigma_{C}{ }^{\prime}=$ $=355.2 \mathrm{MPa}$ at the probability level $P=95 \%$.

The fatigue failures initiating at the surface were found in all rods. In spite of the fact that the $R_{m}$ value is close to that of 50CrMo4 steel crankshaft ( 961 and $928 \mathrm{MPa}$, respectively), the fatigue limits are different. $\sigma_{C}=390 \mathrm{MPa}$ for the present crankshaft and $\sigma_{C}=441 \mathrm{MPa}$ for the previous one at $50 \%$ probability level. However, at $95 \%$ probability level, the situation is opposite: $\sigma_{C}{ }^{\prime}=355.2 \mathrm{MPa}$ and $249.5 \mathrm{MPa}$, respectively.

The oxide-sulphidic inclusions as well as complexes of granular inclusions containing $\mathrm{Al}_{2} \mathrm{O}_{3}$ and $\mathrm{CaO}_{2}$ were found both at surface fatigue initiation sites and at internal sites under the surface. The size of oxide-sulphide inclusions was 70-180 $\mu \mathrm{m}$, exceptionally up to $900 \mu \mathrm{m}$. The size of clusters of granular inclusions was up to $100 \mu \mathrm{m}$, sometimes even $1100 \mu \mathrm{m}$.

The specimens were loaded uniformly across the whole crosssection during the tension-compression tests. Even in regions located 
far from the surface, the formation of secondary initiation cracks on some inclusions was found. It follows from the occurrence of fracture steps diverging from the inclusions. Typical examples of secondary initiation can be seen in Figs. 10 and 11.

According to (4), the critical size of inclusion $a=271 \mu \mathrm{m}$ can be determined for the fatigue limit. This area corresponds to the diameter of $18.6 \mu \mathrm{m}$ in the case of circular particle and to the

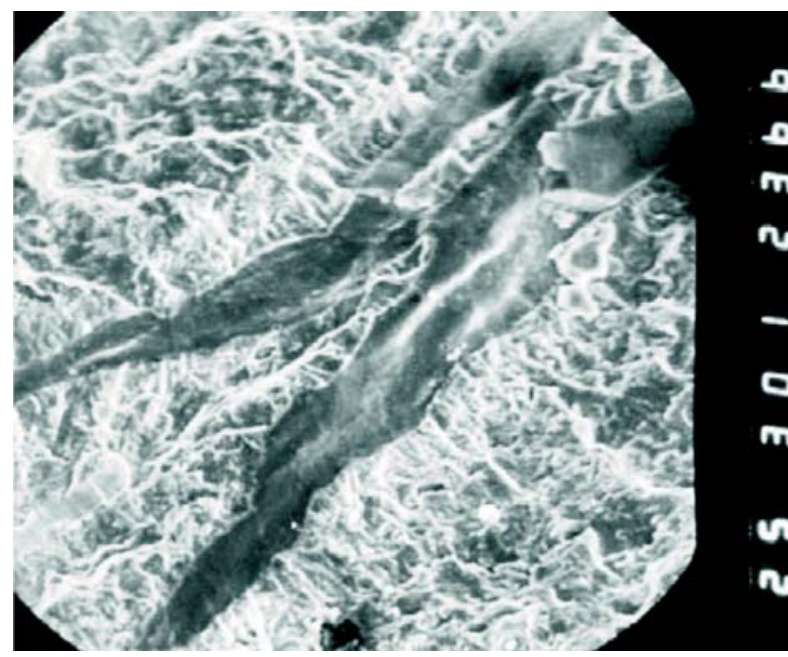

Fig. 10 Secondary initiation cracks at inclusions (sulphide), specimen No. K1 cut from the crankshaft

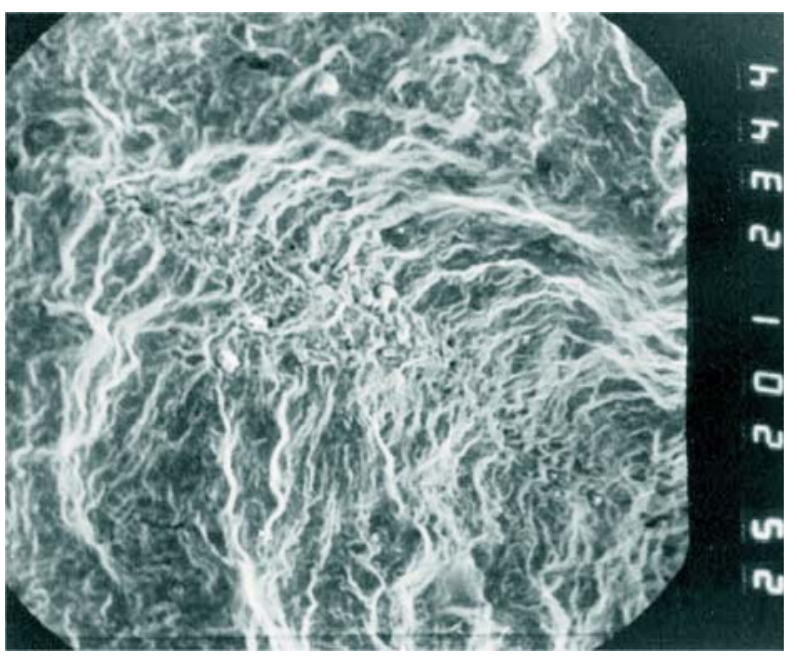

Fig. 11 Secondary initiation cracks at large cluster of granular inclusions, specimen No. K10 cut from the crankshaft size $36.8 \times 7.4 \mu \mathrm{m}$ (ratio 5:1) in the case of prolonged inclusions. Our results suggest that the assessment of the limit inclusion size according to Eq. (4) seems to be very conservative.

\section{Conclusions}

In this paper, results of fatigue tests of tension-compression type in the region of fatigue limit performed on the specimens cut from the massive forgings of alloy steels heat-treated to strength $R_{m}=800-960 \mathrm{MPa}$ are described and discussed. The main results can be summarised as follows:

- Inclusions occurring in heat-treated steels cause very often the initiation of the fatigue failure. However, isolated fine granular inclusions (up to $20 \mu \mathrm{m}$ ), which are present particularly in coarser heat-treated structure, have practically no effect on the fracture initiation.

- According to the results obtained from fatigue tests at tensioncompression with load amplitudes close to fatigue limit, large clusters of granular inclusions with the length exceeding $100 \mu \mathrm{m}$ result in initiation of fatigue failure. This effect was often observed even in cases when the inclusions did not occur on the surface as the area most sensitive to fatigue crack initiation, but inside the specimens. In such the cases, initiation area is often connected with distinct circular, radially growing rosette, which, after reaching the surface, causes fast fatigue failure.

- Secondary initiation nuclei, latent up to $10^{7}$ cycles, were formed during the fatigue tests at some large oxide-sulphide inclusions and at clusters consisting of granular complex inclusions located at the surface. They can result in the formation of fatigue failure after very long lifetime (by several orders higher than $10^{7}$ cycles). The internal initiations with the rosettes can have a similar effect.

- The unfavourable effect of inclusions is dependent first of all on their size, the inclusion type being less important. This fact makes the evaluation of their effect simpler.

- Considering more general fracture mechanics approaches of evaluation of inclusions significance, attention was paid first of all to the procedure according to Murakami et al. (Eqs. (3) and (4)), using the projected area a as the characteristic value. The comparison with our results indicates that this procedure can be useful for engineering orientation, but it is rather conservative and overestimates the adverse effect of inclusions.

\section{Acknowledgement}

This work was carried out within Research Programme MSM 2579700001 supported by the Ministry of Education, Youth and Sport of the Czech Republic.

\section{References}

[1] STRNADEL, B., BUZEK, Z., KUBENA, J.: Problems of Micro-purity of Structural Steels Determined for Demanding Technical Applications (in Czech). Hutnicke listy, 2003, 12, 3 
[2] BAZAN, J., BUZEK, Z., STRANSKY, K., BUZEK, R.: Increase of Steel Purity Using Secondary Metallurgy Method (in Czech). In: Hutnicke listy, 1999, 7-8, 20

[3] LINHART, V., SIGMUNDOVA, J.: Inclusions and their Effect on Fatigue Failure of Heat-treated Parts. In: Materials Engineering, 14, 2007, 3, 13

[4] ABE T., FURUYA Y., MATSUOKA S.: Gigacycle Fatigue Properties of 1800 MPa Class Spring Steels. In: Fatigue \& Fracture of Engineering Materials \& Structures, 27, 2004, 2, 159

[5] CUMMINGS, H.N. et al.: Proceedings of ASTM, 8, 1958

[6] CUMMINGS, H.N., STULEN, F.B. et al.: ASM Handbook, 19, Fatigue and Fracture, ASM International, 1996

[7] LUKAS, P., KUNZ, L.: Small Cracks-nucleation, Growth and Implication to Fatigue Life. In: International Journal of Fatigue, 25, 2003, 9, 855

[8] EL HADDAD, M.H., TOPPER, T.H., SMITH, K.N.: Prediction of non Propagating Cracks. In: Engineering Fracture Mechanics, $11,1979,3,573$

[9] LUKAS, P., KUNZ, L., WEISS, B., STICKLER, R.: Notch Size Effect in Fatigue. In: Fatigue \& Fracture of Engineering Materials \& Structures, 12, 1989, 3, 175

[10] MURAKAMI, Y., ENDO, M.: Effects of Defects, Inclusions and Inhomogeneities on Fatigue Strength. In: International Journal of Fatigue, 16, 1994, 3, 163

[11] MURAKAMI, Y., NOMOTO, T., UEDA, T.: Factors Influencing the Mechanism of Prolonged Fatigue Failure in Steel. In: Fatigue \& Fracture of Engineering Materials \& Structures, 22, 1999, 7, 580

[12] BOMAS, H., LINKEWITZ, T. MAYR, P.: Application of a Weakest-link Concept to the Fatigue Limit of the Baring Steel SAE 52100 in a bainitic condition. In: Fatigue \& Fracture of Engineering Materials \& Structures, 22, 1999, 9, 733

[13] KUNZ, L., LUKAS, P.: Notch Sensitivity of a Steel for Railway Wheels Plates at High Mean Stress. In: Materials Engineering, 10, $2003,1,7$ 